\title{
Temperature, stratification and barnacle larval settlement in two Californian sites
}

\author{
Jesús Pineda ${ }^{\mathrm{a}, *}$, Manuel López ${ }^{\mathrm{b}}$ \\ ${ }^{a}$ Biology Department ms-34, Woods Hole Oceanographic Institution, Woods Hole, MA 02543, USA \\ ${ }^{\mathrm{b}}$ Departamento de Oceanografia Física, Centro de Investigación Cientifica y de Educación Superior de Ensenada, \\ Km 107 Carretera Tijuana-Ensenada, Ensenada, BC 22860, Mexico
}

Received 26 June 2001; received in revised form 11 July 2001; accepted 28 August 2001

\begin{abstract}
Barnacle settlement was monitored in two sites $100 \mathrm{~km}$ apart along the coast of Alta and Baja California. In five periods of observations completed between 1991 and 1996, Chthamalus spp., Pollicipes polymerus, and Balanus glandula settlement was consistently higher in the northern site, La Jolla (LJ), than in the southern site, La Salina (LS). For Chthamalus, the most abundant settler, settlement was higher in LJ in 58 out of 60 paired dates, by a mean factor of 141. In 1996, time series of temperature in about $15 \mathrm{~m}$ of water showed that the stratification was $72 \%$ higher, on average, and that the thermocline was shallower in LJ than in LS. Spectra of temperature showed that internal motions of tidal and higher frequencies were more energetic and closer to the surface in LJ compared to LS. In LJ changes in settlement were positively correlated with changes in stratification. These results suggest that high-frequency internal motions are important in the onshore transport of larvae. Low-frequency cooling events recorded in LJ apparently caused the energetic semidiurnal temperature variability to migrate from the bottom towards the surface, leading to the surface manifestation of the internal tide and surface internal tidal bores, which indicates that the surface nearshore bores occur in response to the shallowing of the thermocline. Tidal and higher frequency internal motions were more energetic when the thermocline was shallow during the low-frequency cooling events, than when it was deep and relatively weak during ordinary conditions. The major cooling event in LJ correlated with the local wind, suggesting local wind-driven upwelling. On the other hand, correlation of LS temperature with LJ temperature, winds, and sea level suggest propagation from the South. These results suggest that the low-frequency drops in temperature that modulate the nearshore internal tidal bores are caused by a combination of the local wind and events that propagate poleward, possibly as coastally trapped waves. (C) 2002 Elsevier Science Ltd. All rights reserved.
\end{abstract}

Keywords: Larval settlement; Larval transport; Stratification; Internal tidal bores; Internal waves

\footnotetext{
*Corresponding author. Tel.: + 1-508-289-2274; fax: + 1508-457-2134.

E-mail addresses: jpineda@whoi.edu (J. Pineda), malope@cicese.mx (M. López).
}

\section{Introduction}

Knowledge of the determinants of recruitment is an important goal in marine population dynamics. For sessile benthic invertebrates, this question has been linked to the more general problem of the factors affecting abundance and distribution. 
Early on, this question was framed as a dichotomy between abundance and distribution as determined by juvenile and adult post-settlement mortality or by larval settlement (Hatton and Fischer-Piette, 1932, p. 5). Starting with Hatton (1938), studies using the experimental manipulative approach attacked the post-settlement side of the issue (e.g. Paine, 1994). The supply of larvae to benthic populations and the importance of geophysical flows to population dynamics have been recurrent themes since the late 1800s (e.g. Young, 1990, for references). However, from the early 1960 s to the late $70 \mathrm{~s}$, nearshore community ecologists largely disregarded larval phenomena. Instead, they banded with terrestrial ecologists and concentrated on local disturbance and biological interactions. Only recently have they began to question the assumption that larval stages are "universally distributed in coastal waters each season", to declare that the next "logical phase" after the study of biological interactions was the study of "the potentially more fundamental source of temporal variation... recruitment variability", and to inquire about the prominence of physical transport processes in determining recruitment variability (Lewis, 1977).

Studies have often found that the rate at which planktonic larvae establish permanent contact with the substrate, settlement rate, is correlated with physical transport (e.g. Hawkins and Hartnoll, 1982). And some studies do not distinguish between settlement rate and larval supply rate-the rate of larval arrival to adult habitats. Settlement rate, however, is dependent on several variables, particularly on suitable substrate area for settlement, a characteristic of the local adult habitat (Bertness et al., 1992; Pineda, 1994b).

Two types of mechanisms have been proposed for explaining the onshore transport of invertebrate larvae in the Pacific coast of North America: (1) internal waves (Norris, 1963; Shanks, 1983) and bores (Pineda, 1991), and (2) the relaxation of wind-driven upwelling (Ebert, 1983; Farrell et al., 1991). Regional variability $(10-100 \mathrm{~km})$ in settlement and recruitment has been explained in the same terms, as due to regional variability in internal motions (Pineda, 1996) and in wind- driven upwelling (Ebert and Russell, 1988; Ebert et al., 1994; Connolly and Roughgarden, 1998). Shanks and Wright (1987) also explained barnacle settlement variability at small scales, $50-300 \mathrm{~m}$, as a result of variability in internal wave transport. However, physical observations for testing these explanations of regional variability are lacking.

Internal motions are ubiquitous phenomena that can explain the onshore transport of larval invertebrates (e.g. Lamb, 1997; Leichter et al., 1998). Internal waves and bores are different mechanisms with dissimilar consequences for larval transport (discussed in Pineda, 1999). Bores often evolve into gravity flows, and while bores and gravity currents are a mass transfer mechanism, waves involve mostly the transfer of energy. In "phase 1", the internal tidal bores produce outcropping of the thermocline (Cairns, 1967; Winant, 1974) and the offshore displacement of nearshore surface water. Then, a few hours later, during phase 2, the flow reverses, the dense cold water migrates offshore, and warm water returns to the shore (Pineda, 1994a, 1999). In Southern California, the return of warm water is often led by a surface warm bore front. Although both phases have been implicated in the onshore transport of larvae, with phase 1 transporting larvae close to the bottom and phase 2 close to the surface, clear evidence of transport only exists for phase 2 (e.g. Pineda, 1994a).

In the Southern California Bight, internal motions explain temperature variability with periods from minutes, to semidiurnal, to fortnightly and monthly (Winant and Bratkovich, 1981; Pineda, 1995); in particular nearshore cooling apparently related to internal tidal bores is more probable 19-24 d after new moon. On the other hand, wind forcing explains diurnal and lower frequency temperature variability (Cairns and LaFond, 1966; List and Koh, 1976; Dorman and Palmer, 1981). Ekman upwelling is weak in the Bight nearshore (Winant and Bratkovich, 1981; Jackson, 1986), but energetic in northern Baja California (Barton and Argote, 1980). There is evidence that low-frequency variability in alongshore currents and sea level along Southern California are related to winds in Baja California (Halliwell and Allen, 1984; Lentz and Winant, 1986). 
The energy of internal tidal motions is dependent on water column stratification and wave amplitude, in itself function of barotropic tidal currents and topography. Stratification influences the energy, the maximum frequency, and the vertical structure of internal motions. For the same amplitude in vertical displacement of isopycnals, stronger water column stratification leads to more energetic internal motions. Low-frequency wind forcing (subtidal, longer time scales than ca. $24 \mathrm{~h}$ ) can significantly affect the nearshore stratification through wind mixing, coastal upwelling, and remotely generated events. This, in turn, may affect the onshore propagation of internal waves and tidal bores by varying the strength of the overall stratification and the depth of the thermocline. Variations in stratification could even inhibit the propagation of internal motions to the nearshore region by completely homogenizing the water column. Surface internal tidal bore warm fronts require a shallow thermocline. In shallow water (ca. $15 \mathrm{~m}$ ), the thermocline is often deep, close to the bottom. Therefore, propagation of internal tidal bores close to the surface and into shallow waters may require a process, such as wind-driven upwelling, that brings the thermocline closer to the surface. On the other hand, vigorous upwelling can outcrop the thermocline and leave a homogeneous water column. Conversely, the relaxation from upwelling can restratify the water column and allow internal wave activity (Rosenfeld, 1990).

The relationship between Southern California internal tidal bores and remote and local lowfrequency phenomena is not known. Here we describe the low-frequency (periods of a few days to about 2 weeks) temperature variability at two sites separated by $100 \mathrm{~km}$ and how this lowfrequency variability affects stratification and hence the amplitude and structure of the highfrequency temperature fluctuations at both sites. Moreover, the low-frequency variability is related at both sites with evidence of propagating events from south to north. We also report barnacle larval settlement at both sites. If high-frequency internal motions transport larvae onshore, one would expect more onshore transport and settlement in sites with stronger water column stratifica- tion. Changes in stratification, which affect the internal motions, may correlate temporarily with changes in onshore larval transport. Our results are consistent with the hypothesis that highfrequency internal motions transport larvae onshore.

\section{Methods}

\subsection{Settlement}

Settlement was measured at two sites along the Southern California (United States) and northern Baja California (Mexico) coastline (Fig. 1). The northern site at La Jolla (LJ) was chosen because several studies have investigated barnacle settlement and physical processes transporting onshore barnacle larvae (Pineda, 1991, 1994b), and because the hydrodynamics and hydrography of the area are well studied (Jackson, 1986, for a review). The southernmost site at La Salina (LS) was chosen

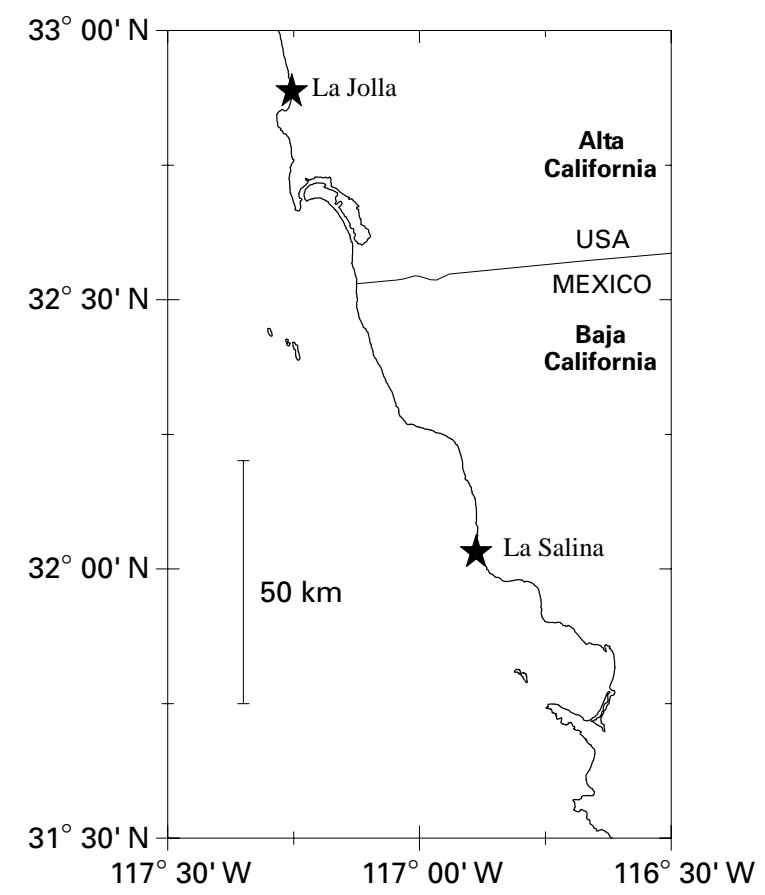

Fig. 1. Settlement and temperature sampling sites. Settlement site at La Jolla was Dike Rock and at La Salina was Las Olas. 
because a very low density of barnacles was observed on several visits between 1985 and 1990, contrasting with the very high densities at LJ (J. Pineda pers. obs.). The two sites were in exposed, open coastlines. Three to nine settlement plates were installed about $8-100 \mathrm{~m}$ apart in the mid-intertidal zone along each shore. Plates within each site were exposed to different physical conditions (e.g. wave action, small scale currents, etc.). Plates were sampled for Chthamalus spp, Pollicipes polymerus, and Balanus glandula spat and attached cyprids. Plates were halved polyvinyl chloride (PVC) pipes $(\sim 2.5 \mathrm{~cm}$ inner diameter $)$ cut through the pipe's longitudinal axis. Three sharp grooves were machined on the interior surface of each ca. $11 \mathrm{~cm}$ long plate, and only settlers close to the groove axis were counted. Most settlers preferred grooves. Groove settlement area per plate was $1.9 \mathrm{~cm}^{2}$. Plates were replaced with clean plates upon removal (see Pineda, 1994b, for other details). Settlers were identified and counted under a dissecting microscope, and plates were scrubbed and washed with fresh water. Attached spat and cyprids are easily identifiable to species (Balanus glandula; Pollicipes polymerus) or genus (Chthamalus spp.)

Five periods of observations were completed between 1991 and 1996; the sampling interval among observation periods varied from 2 to $7 \mathrm{~d}$ (Table 1). The sampling interval within an observation period also varied in two cases. In the third and fifth observation periods, sampling intervals alternated between 3 and $4 \mathrm{~d}$. All 4-d observations in the third and fifth periods were linearly converted to 3 -d sampling intervals.

Settlement differences between the two sites were tested with the Wilcoxon signed-rank test, a non-parametric analogue of the $t$ paired test; date was used for blocking (see Caffey, 1985, for a similar analysis). For all statistical tests, only dates with identical sampling intervals were used. During the observation period corresponding to 1996, the first three settlement dates had very few plates at LJ and LS, and these data were omitted from all statistical tests.

\subsection{Moored observations}

Three moorings, separated from 400 to $900 \mathrm{~m}$ in a direction parallel to the isobaths, were installed at both LS and LJ. At each site, two moorings served as backup, and data from only one mooring per site were analyzed. The bottom depth was about $15 \mathrm{~m}$, and the moorings had temperature loggers at 2, 6, 10, and $13 \mathrm{~m}$ above the bottom (mab). The moorings had only subsurface buoys, which provided high buoyancy for reducing bending by the currents. Moorings were installed in early April 1996 and recovered in late July 1996. One mooring at LS was recovered on 29 April 1996 for inspection and redeployed with fresh instruments on the same date, while the moorings at $\mathrm{LJ}$ were deployed and recovered only once. The Onset Stowaway temperature loggers sampled temperature at a rate of 300 observations per day (sampling interval $=4 \mathrm{~min} 48 \mathrm{~s}$ ). Wind and sea level were recorded at the pier of the Scripps Institution of Oceanography, approximately $200-500 \mathrm{~m}$ from the LJ temperature mooring and settlement sites. Both LJ and LS mooring sites were very close to submarine canyon heads.

Spectral analysis on the raw temperature data was completed on linearly detrended data using the averaged periodogram method of Welch.

Table 1

Sampling dates and intervals in La Jolla and La Salina

\begin{tabular}{lll}
\hline Observation period & Dates & $\begin{array}{l}\text { Target sampling interval/standardized } \\
\text { sampling interval }\end{array}$ \\
\hline First period $n=15$ & 19 April-19 May 1991 & $2 \mathrm{~d} / 2 \mathrm{~d}$ \\
Second period $n=11$ & 15 August-28 September 1991 & $4 \mathrm{~d} / 4 \mathrm{~d}$ \\
Third period $n=11$ & 21 February-30 March 1992 & 3 and $4 \mathrm{~d}(2$ samples per week $) / 3 \mathrm{~d}$ \\
Fourth period $n=1$ & 24-31 May 1995 & 5 and $7 \mathrm{~d} / 7 \mathrm{~d}$ \\
Fifth period $n=28$ & 16 April-9 July 1996 & 3 and $4 \mathrm{~d}(2$ samples per week $) / 3 \mathrm{~d}$ \\
\hline
\end{tabular}


The $\sim 30,000$ observations temperature time series were divided into segments of $2^{12}$ for averaging. Potential energy of internal motions (averaged over a wave period) is given by, P.E. $=g^{2} \overline{\left(\rho^{\prime}\right)^{2}} / 2 \rho_{0} N^{2}$, where $g$ is gravity, $\rho^{\prime}$ are density fluctuations, $\rho_{0}$ is a constant mean density, $N^{2}$ is the square of the Brunt-Väisälä frequency (defined below) and the overbar indicates averaging over a wave period. In order to estimate potential energy at each location, the spectra were multiplied by $g^{2} \rho_{0} \alpha^{2} / 2 N^{2}$ where $\alpha$ is the coefficient of thermal expansion and $N^{2}$ was averaged over the whole observation period at each location. The factor $\rho_{0} \alpha$ multiplying temperature fluctuations, allows an estimate of density fluctuations assuming a linear dependence on temperature only (i.e. no dependence on salinity).

Low-frequency time series of temperature, sea level, and wind were obtained by linearly detrending hourly data and by removing periods $<93 \mathrm{~h}$ using the filter proposed by Godin (1972), in order to suppress tides and higher frequency motions. This effectively suppressed the tidal and higher frequency oscillations. A high-frequency time series was obtained by removing this low-frequency series from the original series. This series thus resolves variability for frequencies between $1 / 51$ cycles per $\mathrm{h}(\mathrm{cph})$ to $1 / 2 \mathrm{cph}$. Empirical orthogonal functions (EOF) for the 2, 6, 10, and $13 \mathrm{mab}$ low-pass and high-pass filtered temperature time series in each site were calculated; the EOF analysis summarizes the vertical structure and the temporal variability of the four time series at each location (see Emery and Thomson, 1997). The Brunt-Väisälä frequency for waters between pairs of loggers (2-6, 6-10, and 10-13 mab) was also derived from the low-frequency time series and a constant salinity value of 34 psu. The BruntVäisälä frequency squared, a measure of stratification, was calculated as

$N^{2}=-\frac{g}{\rho_{0}} \frac{\partial \rho}{\partial z}$,

where $\rho$ is water density filtered to eliminate highfrequency motions and $z$ is depth. The square root of $N^{2}$ gives the maximum frequency of oscillation for internal waves. The LJ winds, used in the wind and temperature correlations, were the alongshore component, $101^{\circ}$ counterclockwise from the East. Effective degrees of freedom for the correlation functions were estimated by using the method proposed by Chelton (1983) (see Emery and Thomson, 1997, p. 259). Note that the number of effective degrees of freedom should be considered as a rough estimate, because the actual value varies depending on the maximum lag taken for the auto- and cross-correlation functions. Here we calculated correlation functions to maximum lags of $20 \%$ of the series (roughly equivalent to $400 \mathrm{~h}$ ) for the estimation of the number of degrees of freedom. An examination of a few of the correlation functions showed that at those lags, the function was well past its first zero crossing, possibly underestimating the number of degrees of freedom.

\section{Results}

\subsection{Settlement}

Overall, settlement was higher at LJ than at LS (Table 2; Fig. 2; figures for settlement periods 1-4 are not shown because there are no concurrent physical measurements). During the fourth period, average Chthamalus settlement standardized for $7 \mathrm{~d}$ was 638 at LJ and 21 at LS, and there were neither Pollicipes nor Balanus settlement. There was evidence of statistical differences in Chthamalus settlement between LJ and LS in periods 1, 2, 3 and 5 (Table 3). For Pollicipes and Balanus, on the other hand, there was evidence of statistical differences in only two out of four periods (Table 3). Chthamalus settlement was higher than that of Pollicipes and Balanus (Table 2). Chthamalus settlement at LJ was high during all of the observation periods, while Balanus settlement tended to be high only in periods 1 and 3, corresponding to late winter and spring. During the fifth observation period, Chthamalus peaks at LJ and LS appeared to coincide with colder waters (Figs. 2-4). On 7-10 May and 28 June, settlement coincides with colder waters close to the bottom, but the surface water temperature lags the bottom water temperature several days. 
Table 2

Mean and standard deviation (SD) for raw barnacle settlement per $\mathrm{cm}^{2}$

\begin{tabular}{|c|c|c|}
\hline Observation period & La Jolla & La Salina \\
\hline \multicolumn{3}{|l|}{ Chthamalus } \\
\hline \multicolumn{3}{|l|}{ First period } \\
\hline Mean (SD) & $108.08(69.49)$ & $0.79(0.91)$ \\
\hline \multicolumn{3}{|l|}{ Second period } \\
\hline Mean (SD) & $222.73(97.50)$ & $5.42(8.07)$ \\
\hline \multicolumn{3}{|l|}{ Third period } \\
\hline Mean (SD) & $231.34(154.58)$ & $40.20(22.14)$ \\
\hline \multicolumn{3}{|l|}{ Fifth period } \\
\hline Mean (SD) & $262.08(150.10)$ & $38.59(56.66)$ \\
\hline \multicolumn{3}{|l|}{ Pollicipes } \\
\hline \multicolumn{3}{|l|}{ First period } \\
\hline Mean (SD) & $13.80(20.87)$ & $0.04(0.07)$ \\
\hline \multicolumn{3}{|l|}{ Second period } \\
\hline Mean (SD) & $0.35(0.65)$ & $0.05(0.11)$ \\
\hline \multicolumn{3}{|l|}{ Third period } \\
\hline Mean (SD) & $0.10(0.30)$ & $0.01(0.05)$ \\
\hline \multicolumn{3}{|l|}{ Fifth period } \\
\hline Mean (SD) & $30.21(72.63)$ & $0.06(0.12)$ \\
\hline \multicolumn{3}{|l|}{ Balanus } \\
\hline \multicolumn{3}{|l|}{ First period } \\
\hline Mean (SD) & $3.07(10.28)$ & $0.00(0.00)$ \\
\hline \multicolumn{3}{|l|}{ Second period } \\
\hline Mean (SD) & $0.00(0.00)$ & $0.00(0.00)$ \\
\hline \multicolumn{3}{|l|}{ Third period } \\
\hline Mean (SD) & $5.96(7.70)$ & $0.01(0.02)$ \\
\hline \multicolumn{3}{|l|}{ Fifth period } \\
\hline Mean (SD) & $0.42(1.19)$ & $0.00(0.00)$ \\
\hline
\end{tabular}

Sampling periods for each observation period are given in Table 1.

\subsection{Moored temperature}

Mean temperature at LS was colder, on average, than at $\mathrm{LJ}$, except close to the bottom where LJ bottom waters were slightly colder. Maximum temperatures at $\mathrm{LJ}\left(\right.$ e.g. $>22^{\circ} \mathrm{C}$ ) were never observed at LS. Overall, the mean water temperature was about $1{ }^{\circ} \mathrm{C}$ lower at $\mathrm{LS}$ than at $\mathrm{LJ}$ (Table 4). The temperature time series at $\mathrm{LJ}$ and LS showed high variability at high frequencies (Fig. 3), with larger high-frequency variability (std. dev.) at all depths at LJ than at LS. On the other hand, low-frequency variability (std. dev.) was lower at the near surface waters of LJ than in those of LS (Table 4). There were also low-frequency variations in temperature that occurred at both sites. An increase in temperature was observed in early May, while sharp drops occurred on 17 and 18 May and 27 and 28 June (Fig. 4). In LJ, the energetic high-frequency variability moved from the bottom to the near surface with the drops. This was particularly clear for the June event.

The low-frequency temperature first EOF time series at LJ and LS were well correlated. Moreover, the temperature at LS led the temperature at LJ by $40 \mathrm{~h}$, which is appropriate for poleward propagation (Table 5). (The low-frequency individual time series were also well correlated and with lags appropriate for poleward propagation, but for brevity, results are not presented here.) The sea level at LJ was correlated with the temperature EOF at LS, but not with the one at LJ. Thus, sea level at LJ correlated significantly with the distant temperature at LS, but not with the local one at LJ. The two low-frequency drops in temperature coincided with upwelling-favorable winds (Fig. 4). The LJ winds correlated with the temperature EOFs at LJ and LS, with a lower correlation for LJ than for LS. The wind at LJ led the temperature EOFs at LJ and LS, with a larger lag at LJ than at LS. Finally, the LJ winds were not correlated with the LJ sea level (Table 5).

Surface to bottom water temperature differences were smaller at LS than at LJ. The $N^{2}$ values were generally larger at LJ than at LS (Fig. 5). Maximum stratification often occurred at 8 mab, but during the late June temperature drop maximum values moved shallower to $11.5 \mathrm{mab}$. This displacement towards the surface of the maximum buoyancy frequency is less obvious at LS. At LJ, maximum buoyancy frequency remained high after the drop in temperature, contrasting with LS where there was an overall decrease in stratification.

Power spectral density plots of temperature (appropriately scaled to reflect potential energy, as pointed above) show that diurnal frequencies at LJ and LS were energetic at all depths (Fig. 6; results shown only for the most contrasting spectra, the 10 and 2 mab depths). Peaks in given spectrum frequencies indicate that a large proportion of the variance in the time series is explained by variance at these frequencies. The semidiurnal 


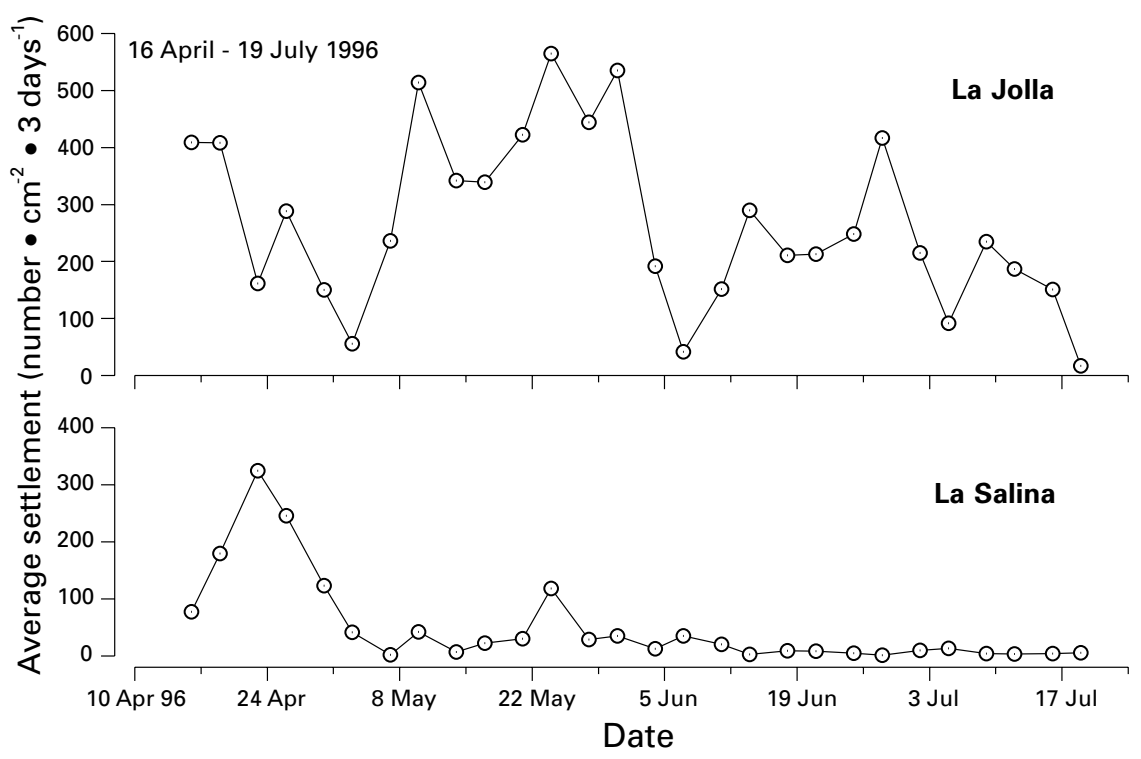

Fig. 2. Chthamalus spp. mean settlement per $\mathrm{cm}^{2}$ per $3 \mathrm{~d}$ from April to July 1996.

Table 3

Wilcoxon tests of differences among sites using the 2-sided normal approximation

\begin{tabular}{lllc}
\hline & Taxa & $z$ statistic & $P$ 2-tailed \\
\hline First period & Chthamalus & -3.180 & $<0.01$ \\
$n=13$ & $\begin{array}{l}\text { Pollicipes } \\
\text { Balanus }\end{array}$ & -2.497 & $<0.013$ \\
& & & 0.109 \\
Second period & Chthamalus & -2.666 & $<0.01$ \\
$n=9$ & Pollicipes & -0.730 & 0.465 \\
& Balanus & - & - \\
Third period & Chthamalus & -2.667 & $<0.01$ \\
$n=11$ & Pollicipes & -0.447 & 0.655 \\
& Balanus & -2.383 & $<0.05$ \\
Fifth period & Chthamalus & -4.015 & $<0.001$ \\
$n=21$ & Pollicipes & -3.920 & $<0.001$ \\
& Balanus & -2.371 & $<0.05$ \\
\hline
\end{tabular}

Only dates with identical sampling intervals were used. Balanus statistics for the second period were impossible to calculate, as all data equals zero.

frequency at the two sites is very energetic at 2 mab. It is also energetic at $\mathrm{LJ}$ at 10 and 13 mab. However, it is relatively weaker at LS at 10 and $13 \mathrm{mab}$. The higher frequency end of the spectrum tends to be generally more energetic at LJ than at
LS, except at the deepest instrument. These differences in energy are consistent with the larger near-surface stratification at $\mathrm{LJ}$ as compared to LS. However, larger amplitude internal waves at LJ could also be contributing to the higher energy levels observed there.

The vertical structure of high-frequency temperature fluctuations for two representative periods, when the stratification was relatively weak and uniform, but somewhat larger at the bottom and mid-depth (beginning of the record to 5 May) and when the thermocline was close to the surface (29 June to the end of the record, see Fig. 5), was investigated using EOFs. An EOF analysis of the four temperature high-frequency time series at each site for each of the two periods yielded a nondimensional time series and a dimensional vector containing the vertical structure of the data, where the values in ${ }^{\circ} \mathrm{C}$ are a measure of the amplitude (Fig. 7). During the first period when the stratification was weak and almost uniform, the largest amplitudes occurred close to the bottom at both LS and LJ; the amplitudes at LJ were about double those of LS. During the cooling events, the maximum amplitudes at LS increased slightly and migrated from the bottom to mid-depths. At LJ, the maximum amplitudes migrated closer to the 


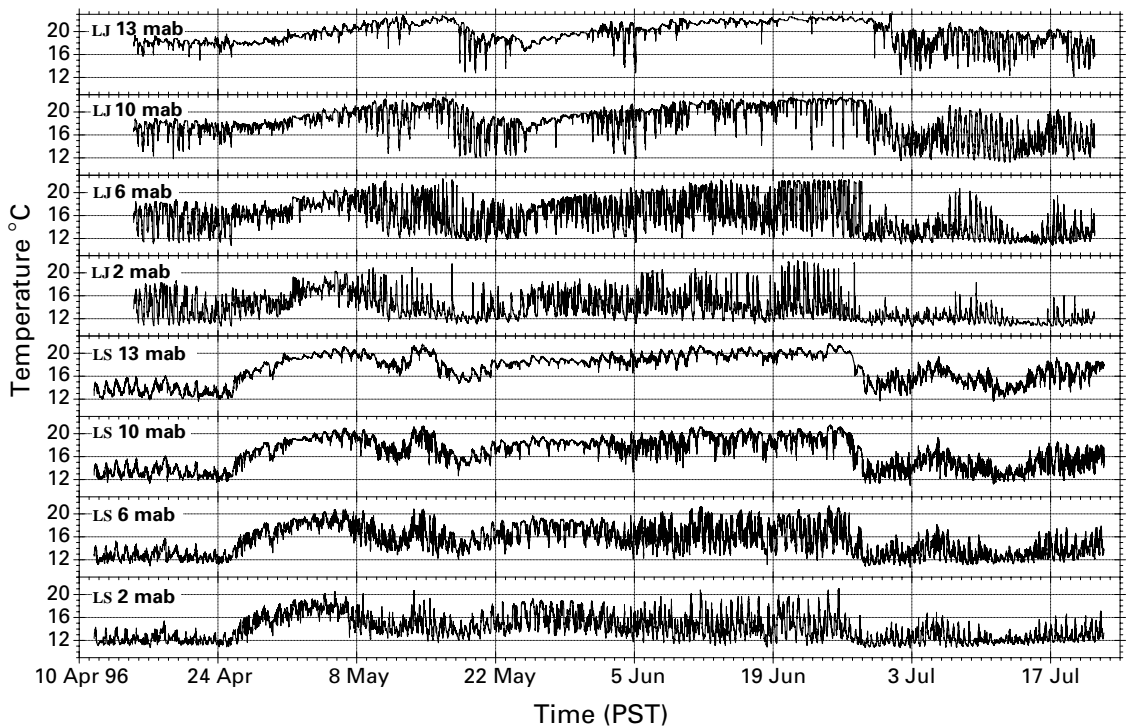

Fig. 3. Raw temperature observations at LJ and LS.

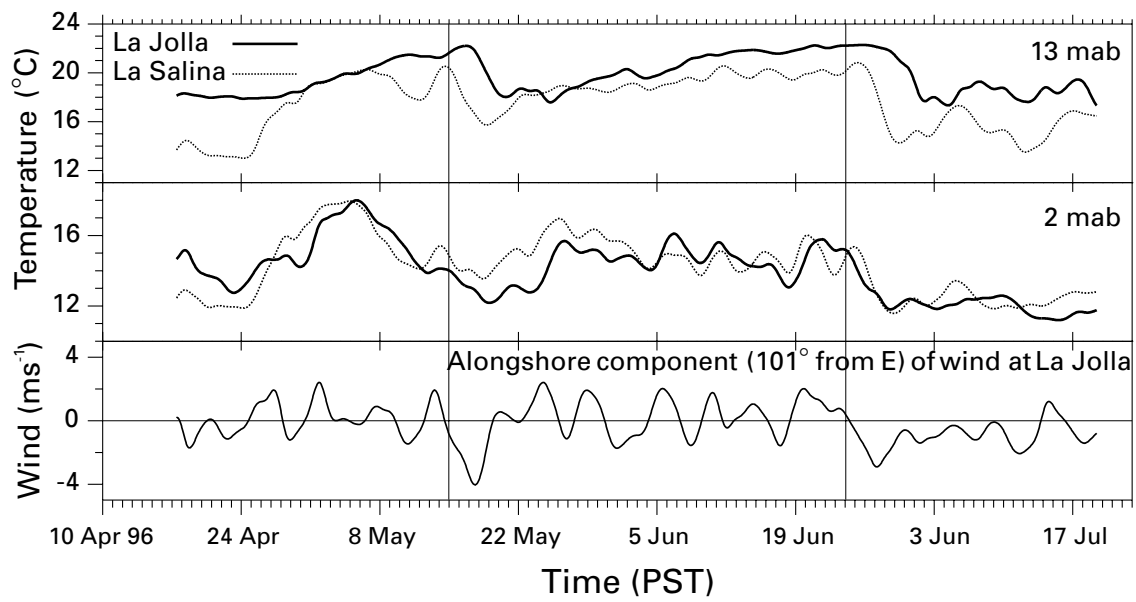

Fig. 4. Low-frequency time series of temperature and wind at LJ and at LS. Vertical lines on 15 May and 24 June point to onset of cooling events.

surface and peaked at 10 mab. Maximum amplitudes at LJ were more than double those of LS, which is consistent with the greater stratification near the surface at LJ (see Fig. 5). LJ amplitudes were remarkably larger during the cooling event than during periods when the stratification was almost uniform. Clearly, the stratification at LJ can support greater amplitude, high-frequency (tidal and higher) temperature fluctuations than that at LS. Moreover, these fluctuations were considerably larger when the thermocline rose due to low-frequency cooling events.

We used a non-parametric Spearman test, to determine whether changes in Chthamalus settlement, the most abundant settler, were correlated with changes in stratification. No analysis was completed for Pollicipes and Balanus because of their low settlement. Change in mean settlement 
Table 4

Statistics for raw and filtered temperature time series. Start and end time is the same for LJ and LS

\begin{tabular}{|c|c|c|c|c|}
\hline $\begin{array}{l}\text { Raw } \\
\text { data } \\
n=29,087\end{array}$ & $\begin{array}{l}\text { Mean } \\
\text { (raw } \\
\text { data) }\end{array}$ & $\begin{array}{l}\text { Standard } \\
\text { deviation }\end{array}$ & $\begin{array}{l}\text { Standard } \\
\text { deviation } \\
\text { (low- } \\
\text { frequency) }\end{array}$ & $\begin{array}{l}\text { Standard } \\
\text { deviation } \\
\text { (high- } \\
\text { frequency) }\end{array}$ \\
\hline La Jolla & $\begin{array}{l}\text { All depths } \\
16.96\end{array}$ & & & \\
\hline $2 \mathrm{mab}$ & 14.0 & 2.3 & 1.6 & 1.5 \\
\hline $6 \mathrm{mab}$ & 15.9 & 2.9 & 2.1 & 1.9 \\
\hline $10 \mathrm{mab}$ & 18.3 & 2.7 & 2.1 & 1.5 \\
\hline $13 \mathrm{mab}$ & 19.7 & 1.9 & 1.6 & 0.9 \\
\hline La Salina & $\begin{array}{l}\text { All depths } \\
16.00\end{array}$ & & & \\
\hline $2 \mathrm{mab}$ & 14.2 & 2.2 & 1.7 & 1.2 \\
\hline $6 \mathrm{mab}$ & 15.4 & 2.5 & 2.0 & 1.3 \\
\hline $10 \mathrm{mab}$ & 16.8 & 2.6 & 2.4 & 0.8 \\
\hline $13 \mathrm{mab}$ & 17.5 & 2.4 & 2.3 & 0.6 \\
\hline
\end{tabular}

and change in mean stratification in 1996 were calculated as the difference between consecutive settlement dates for each time series. Differencing is a type of filter useful in geophysical time series that removes trends which may result in spurious correlations (e.g. Chatfield, 1989). Mean stratification values were obtained by averaging data from 4,8 , and $11.5 \mathrm{mab}$. There was evidence that change in settlement at LJ correlated with change in the Väisälä frequency $\left(r_{\mathrm{s}}=0.49 ; p<0.05\right.$; Fig. 8$)$. No statistical evidence of correlation was found for Chthamalus settlement at LS.

\section{Discussion}

Our observations indicate that the low-frequency, wind-driven uprising of the thermocline modulated the internal tidal bores, that this effect varied depending on the local stratification, and that local upwelling and coastally trapped waves may be related to this low-frequency forcing. The site with highest stratification had highest settlement, and temporal changes in stratification at $\mathrm{LJ}$ correlated with temporal changes in settlement. These results are consistent with the hypothesis that internal motions transport planktonic larvae onshore.
Table 5

Maximum lagged correlations between various low-frequency time series

\begin{tabular}{|c|c|c|c|}
\hline$r$ (lag, DF) & $\begin{array}{l}\text { First EOF } \\
\text { of } T \text { at } \mathrm{LJ}\end{array}$ & $\begin{array}{l}\text { First } \\
\text { EOF of } \\
T \text { at LS }\end{array}$ & $\begin{array}{l}\text { Sea Level } \\
\text { at LJ }\end{array}$ \\
\hline $\begin{array}{l}\text { First EOF } \\
\text { of } T \text { at LS }\end{array}$ & $\begin{array}{l}0.86 \\
(40,7)^{* *}\end{array}$ & & \\
\hline $\begin{array}{l}\text { Sea Level } \\
\text { at LJ }\end{array}$ & $\begin{array}{l}0.42 \\
(31,18) \mathrm{ns}\end{array}$ & $\begin{array}{l}0.54 \\
(7,15)^{*}\end{array}$ & \\
\hline $\begin{array}{l}\text { Alongshore } \\
\text { wind at LJ }\end{array}$ & $\begin{array}{l}0.44 \\
(56,114)^{* *}\end{array}$ & $\begin{array}{l}0.53 \\
(34,45)^{* *}\end{array}$ & $\begin{array}{l}0.28 \\
(105,46) \mathrm{ns}\end{array}$ \\
\hline
\end{tabular}

Alongshore wind is $101^{\circ}$ anticlockwise from E. The first EOFs of temperature at LJ and LS explain $85 \%$ and $95 \%$ of the total low-frequency variance. Lag of maximum correlation (in h) and an estimate of the effective degrees of freedom, respectively, are given in parenthesis. Positive lags means that the series in the row leads the series in the column. ns $=$ non significant, $*=p<0.05, * *=p<0.01$.

\subsection{Alongshore and temporal variability in temperature and stratification}

\subsubsection{Alongshore lags and drops in temperature: local upwelling and remote propagation}

Low-frequency temperature fluctuations at LS and LJ are well correlated (Table 5), with fluctuations at LS leading those at LJ. Winant (1983) found that temperature remained coherent over scales of about $50 \mathrm{~km}$ in Southern California. However, he found no evidence of propagation, since his maximum correlations occurred at zero lag. Similarly, Barton (1985) found coastal temperatures along northern Baja California to be well correlated over alongshore scales up to $350 \mathrm{~km}$, but, except for one case, with no evidence of propagation. In the correlation between Rosarito and Ensenada, which overlaps part of our study area, Barton did find the largest correlation at a lag of about $1 \mathrm{~d}$. In his article he did not state which record leads but he has confirmed us that the southern station lead the one to the north (Barton, pers. comm.). In contrast, the relatively large correlations and corresponding lags found here do support the idea of alongshore propagation at speeds ranging from 0.4 to $1.5 \mathrm{~m} \mathrm{~s}^{-1}$ (based on the lags of the individual temperature time 


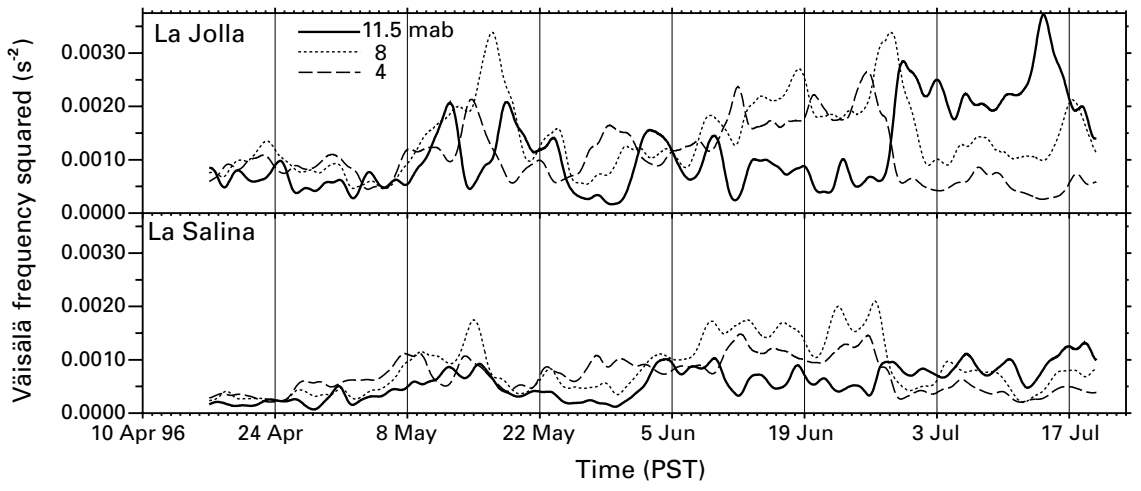

Fig. 5. Brunt-Väisälä frequency of the low-frequency temperature calculated among pairs of temperature loggers.

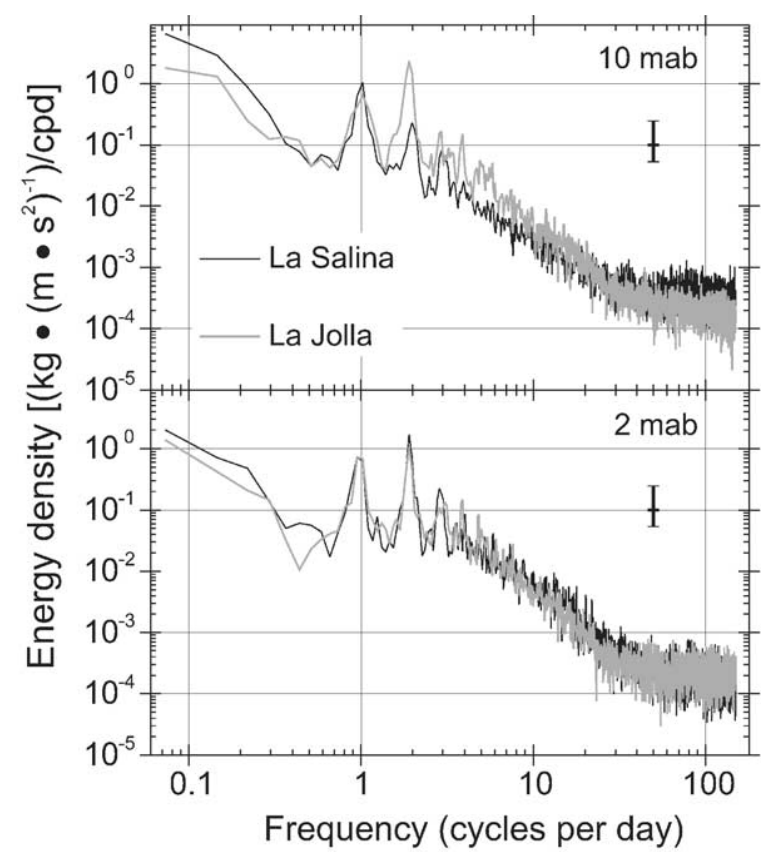

Fig. 6. Power spectral density of temperature for LS and LJ at 2 and $10 \mathrm{~m}$ above the bottom (mab) with $95 \%$ confidence intervals. Spectra have been appropriately scaled to reflect potential energy at each location (see text).

series at each depth), typical of coastally trapped waves (e.g. Chapman, 1987). The discrepancy with the Winant and Barton studies could be due to different environmental conditions. In any case, it is impossible to establish unambiguously propagation solely from the correlation of temperature records at two locations. Nevertheless, other

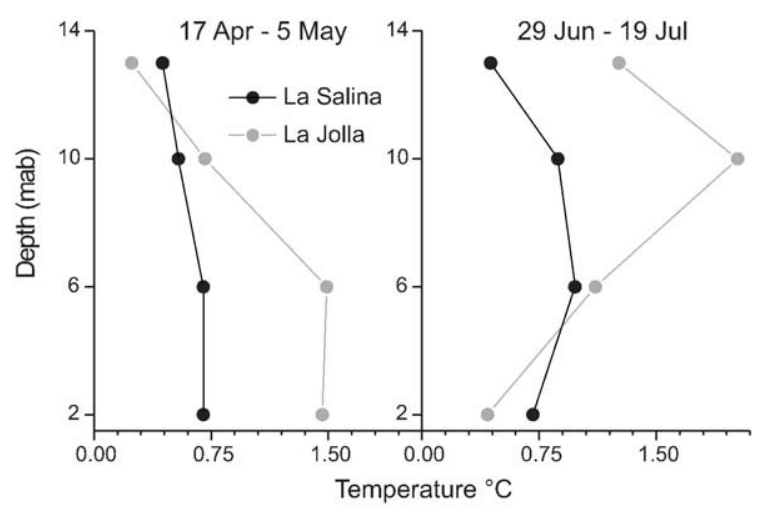

Fig. 7. First dimensional EOF of the high-frequency time series for two different periods in conditions where the thermocline was close to the bottom (left panel) and close to the surface (right panel). The first period lasts about $18 \mathrm{~d}$ and the second period lasts about $21 \mathrm{~d}$. These EOFs explain $86 \%$ and $76 \%$ of the total variance at LJ during the first and second periods, respectively, and $77 \%$ and $70 \%$ at LS.

available evidence also suggests poleward propagation, as discussed below.

Correlations of LJ sea level with temperature at LJ were slightly lower (and non-significant) and at a greater lag than those at LS (see Table 5). The greater lags of sea level with temperature at LJ may reflect that the initial sea level response is locally faster than that of temperature (e.g. Huyer et al., 1979) and in consequence the sea-level signal would start to propagate earlier than that of temperature. If part of the response at $\mathrm{LJ}$ is propagating from the south, then the sea-level 


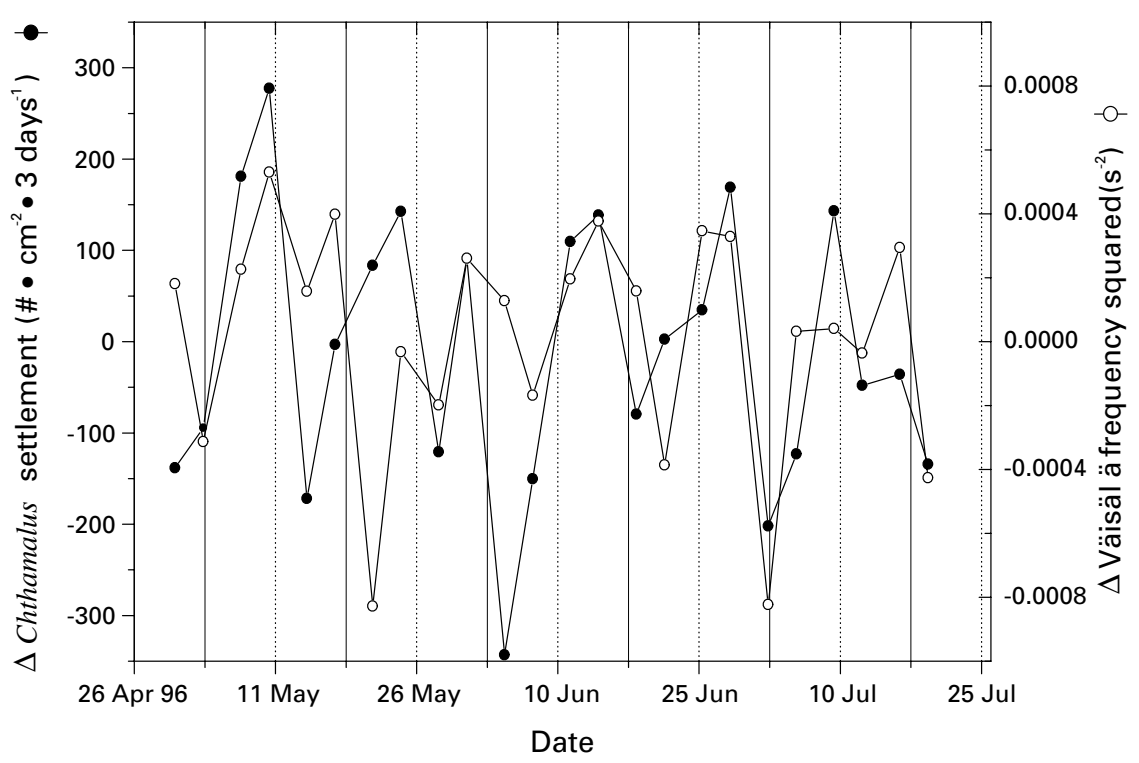

Fig. 8. Changes in Chthamalus settlement and changes in stratification at LJ.

signal would arrive at LJ before the temperature signal, which is responding with a larger time lag than the sea level. This would explain the smaller lags of LJ sea level with temperature at LS. Furthermore, lags of wind at LJ with temperature at LS are also smaller than lags with the local temperature at LJ (see Table 5), supporting the idea that part of the signal is wind forced and propagating from the south.

Fig. 4 supports the idea that the two major drops in temperature at LJ and LS are due to coastal upwelling. But this does not necessarily contradict the idea of propagation from the south. Wind has been found to be fairly coherent between San Diego and Ensenada (Barton, 1985) and within Southern California over distances of at least $80 \mathrm{~km}$ (Lentz and Winant, 1986). Amplitudes of the offshore Ekman transport, the forcing agent of coastal upwelling, appear to grow towards the south, to a maximum at about $29^{\circ} \mathrm{N}$ (Bakun and Nelson, 1976). Lentz and Winant (1986) also found that geostrophic winds along Baja California were correlated with alongshore adjusted sealevel gradients in Southern California. Therefore, the cooling events seen at LJ could be a combination of local upwelling and upwelling propagating from the south due to the same wind forcing, perhaps with a larger amplitude.

\subsubsection{Hypothesis that near-surface internal tidal} bores result from the shallowing of the thermocline

We propose that low-frequency wind-driven events modulate the nearshore internal tidal bores. Low-frequency wind-driven events would produce shallowing of the thermocline. This shallowing would allow the surface manifestation of the internal tide in the nearshore, and also the nearshore internal tidal bores and gravity currents. Before the occurrence of the major low-frequency cooling that coincides with upwelling-favorable winds (see Fig. 4), the internal wave activity is concentrated mainly near the bottom. But when these cooling events reach the surface (i.e., a raising of the thermocline), there is an increase in internal wave activity at mid-depths and near the surface (Figs. 3 and 7). Surface internal bores occur in response to the raising of the thermocline, and they can be detected in Fig. 3 by sharp diurnal or semidiurnal changes in shallow water temperature. In fact, each one of the low-frequency cooling events at LJ resulted in groups of internal tidal bores, and the bores described in Pineda (1999) 
coincided with the second cooling event. These results also explain the negative correlation between surface temperature and daily barnacle settlement reported by Pineda (1991). However, the relationship between temperature and settlement must be more complex than a simple negative relationship, because physical transport can occur in the absence of larvae to be transported (see below, at the end of "Settlement and water column stratification"). In the cooling events shown in Fig. 4, the stratification in the thermocline remained high at LJ. However, it did not remain high at LS, where internal wave activity was much reduced. This suggests that further cooling and outcropping of the isotherms reduced the overall stratification, eventually inhibiting the propagation of internal tidal bores to the shallower waters. Upwelling, or some other mechanism that raises the thermocline, may allow onshore transport of material to reach the coast during part of the event. However, once the nearshore waters are sufficiently homogenized, the onshore transport may be inhibited. This idea is supported by differences in stratification and larval settlement at LJ and LS, as discussed below.

Our explanation that local or remotely forced wind-driven events appear to modulate the expression of internal tidal bores differs from that of Pineda (1991, 1995), who argued that the modulation was associated with some tidal forcing varying at fortnightly and monthly periods, although the exact mechanism was unspecified. Still, these hypotheses are not mutually exclusive since internal tidal bores could be modulated by both, lowfrequency variations in stratification (wind driven and propagating from the south) and, for example, by the spring-neap cycle in the amplitude of the tides. This latter mechanism is presumably responsible for variations of the amplitude of the tidal internal waves at the generation region.

\subsection{Differences in settlement among taxa}

Overall, Chthamalus settlement was higher than that of Pollicipes and Balanus. Chthamalus is by far the most abundant barnacle in the region (Ricketts and Calvin, 1968; Morris et al., 1980). A previous study at $\mathrm{LJ}$ found more and less variable settlement for Chthamalus than for Pollicipes, although occasional massive Pollicipes settlements were higher than maximum settlement values for Chthamalus (Pineda, 1994b). Chthamalus settlement was high during all observation periods. Balanus glandula settlement peaked in the spring, with low settlement in the summer. Balanus glandula is near to its southern geographic limit in the sampling localities (Morris et al., 1980). More settlement for Chthamalus than for the other taxa is consistent with the idea that overall larval abundance and settlement were correlated with adult abundance.

\subsection{Settlement and water column stratification}

Assume that internal motions transport planktonic larvae onshore. If energetic internal waves and bores depend on strong stratification, then weaker stratification would reduce the energy of the internal motions, causing a decrease in onshore larval transport. It then follows that alongshore differences in stratification should produce regional variability in onshore larval transport and settlement, with more settlement at sites where stratification is well developed and less at sites associated with weaker stratification (Pineda, 1996). Our results are consistent with the hypothesis that regional differences in settlement and larval transport are related to alongshore variability in stratification and internal motions. However, other factors could also be responsible for the alongshore differences in settlement, and our results are only suggestive (see below).

Stratification was $72 \%$ higher on average at $\mathrm{LJ}$ than at LS. If wave amplitude (vertical displacement of isopycnals) was similar at both sites, then higher stratification implies that water column at LJ is capable of sustaining more energetic highfrequency motions than the water column at LS. This capability was realized. The power spectra show that internal motions of higher frequency than semidiurnal were more energetic at LJ than at LS at all depths but the bottom. Actually, we can estimate the potential energy of the high-frequency motions by integrating the spectra in Fig. 6 (and corresponding ones at depths not shown). To 
estimate kinetic energy, the potential energy at each frequency is multiplied by a factor that depends on frequency, Coriolis parameter, and $N^{2}$ (Gill, 1982, p. 267) and the results integrated over a range of frequencies. For frequencies $>2 \mathrm{cpd}$, this exercise gave a ratio of kinetic energy at $\mathrm{LJ}$ to kinetic energy at LS of $0.8,1.7,3.3$, and 2.3 for depths of $2,6,10$, and $13 \mathrm{~m}$ above the bottom, respectively. The corresponding ratios for potential energy were only slightly lower than the ones for kinetic energy. The high-frequency band would include the internal motions that transport the larvae.

Temporal changes in Chthamalus settlement at LJ were correlated with changes in stratification, although the correlation was weak and no correlation was found at LS. This further supports the hypothesis that internal motions cause onshore larval transport at $\mathrm{LJ}$ and settlement and agrees with the previous result that peaks in settlement correlate with drops in surface water temperature (Pineda, 1991) which in turn correlate with increased near surface stratification (this contribution). This correlation, however, should be viewed with caution. First, the relationship between changes in stratification and changes in settlement appears more complicated than a simple monotonic relationship, which is what the correlation analysis tests, and it may not hold under certain conditions. For example, the major and most extended peak in LJ Chthamalus settlement in 1996, which started between 17 and 21 May (Fig. 2), did not correspond to an overall increase in stratification. It started with a drop in near surface water temperature in 17 May (see Fig. 4) that generated a group of internal tidal bores (from 17 to 24 May, note the sharp variability in shallow water temperature in the LJ $13 \mathrm{mab}$ logger, Fig. 3). In that event, stratification decreased at the bottom while it increased at middepths and at the surface. It is also obvious that a patchy larval pool could upset temporal correlation between a physical variable and settlement; no correlation would be found even in cases where physical transport actually occurs when there are no larvae in the larval pool. Temporal variations in the internal wave amplitude (by the spring-neap tidal cycle, for example) could also be degrading the correlation between settlement and stratification.

\subsection{Other explanations for differences in settlement at $L J$ and $L S$}

Settlement rate is dependent on larval supply and the amount of suitable substrate for settlement. Although other factors such as gregarious behavior also affect settlement, larval supply and amount of suitable substrate for settlement appear to be the most important for regional and temporal comparisons within a species. Evaluating the relative importance of suitable substrate on settlement rates in field conditions appears to be a formidable task, because this requires a detailed knowledge of larval flux, small-scale hydrodynamics, and larval behavior (discussed in Pineda and Caswell, 1997); to our knowledge, no published study has evaluated the relative importance of supply and amount of suitable substrate in field conditions. We did not evaluate the effects of amount of suitable substrate on settlement rates. Our sampling covered periods where suitable substrate at LJ was both abundant and scarce, when the intertidal zone was inundated by sand, mostly in summer (e.g. Taylor and Littler, 1982). Inundation by sand reduces the amount of suitable substrate for settlement (Pineda, 1994b). On the other hand, amount of suitable substrate always appeared abundant at LS, a site which is apparently not inundated by sand (J. Pineda pers. obs.). If the amount of suitable substrate would largely determine the differences in settlement rates at LJ and LS, one would expect small or no differences when suitable substrate is abundant. Yet, settlement was larger at LJ than at LS in 58 out of 60 dates. In particular, Chthamalus settlement was much larger at LJ than at LS in sampling periods 1 and 3 (21 February-19 May; Table 1), corresponding to seasons where amount of suitable substrate would be expected to be abundant at both LJ and LS, a period where one would expect no differences in settlement rates due to differences in suitable substrate. Settlement and recruitment estimations can also be influenced by settlement measuring interval (Michener and Kenny, 1991). In this study, settlement interval was kept short 
and constant, and did not differ among sites, thereby reducing its potential to affect our comparisons.

Because larval abundance close to the settlement sites depends on physical transport and the larval pool, full understanding can only be reached by observing both physical transport and the larval pool. We did not quantify the larval pool, and therefore we cannot determine the relative importance of internal motions, but only suggest its role. Our results that in LS differences in settlement did not correlate with differences in stratification suggest that internal motions may be unimportant in that area. This result could also be explained, however, by a less abundant and patchy larval pool or temporal variation in internal wave amplitude, as pointed above.

\subsubsection{Alternative hypotheses}

Our results are inconsistent with hypotheses that argue that low settlement is the result of the offshore drift of larvae due to offshore Ekman transport, and that pulses in settlement result from the relaxation of Ekman upwelling (Ebert, 1983; Roughgarden et al., 1988; Farrell et al., 1991). Colder water is often associated with wind-driven upwelling, and colder water at LS could be used to argue that low settlement at LS was caused by wind driven Ekman upwelling. However, most settlement at LS occurred during cooling events (Figs. 2 and 4). Settlement at LJ also coincided with cooler water, possibly due to Ekman upwelling, the opposite prediction of the Ekman upwelling hypothesis (Le Fèvre and Bourget, 1992). In summary, there was not a significant positive correlation between near-surface water temperature and settlement for LS or for LJ. On the contrary, in the case of LS, the correlations were negative and statistically significant. The fact that wind driven Ekman upwelling may modulate internal motions in unaccounted ways, as suggested by our results that the shallowing of the thermocline appears to induce the bores, complicates the task of identifying mechanisms of larval transport. Furthermore, internal motions occur also during periods of Ekman upwelling relaxation (e.g. Rosenfeld, 1990).

\section{Conclusions}

Our results support the predictions of the internal tidal bore hypothesis, which argues that stratification modulates onshore larval transport and settlement. However, the relationship between changes in settlement rate and changes in stratification does not appear to be linear. The magnitude and vertical structure of the stratification during ordinary and low-frequency cooling events was dependent on the site's local regime. Internal tidal bores were modulated by the low-frequency variations in stratification, possibly related to upwelling and coastally trapped waves, and at LJ, the energy of the high-frequency internal waves increased during these events. Our results do not represent a rigorous test of the hypothesis linking stratification and settlement because of the limited number of sites, and because we did not quantify the larval pool. Moreover, energy of internal motions depends of amplitude, as well as on stratification. Our study does not appear to support hypotheses about the role of wind-driven upwelling on larval transport and recruitment, including little onshore larval transport and recruitment due to offshore larval drift during Ekman upwelling and onshore transport and increased settlement during relaxation. On the contrary, local and remote winddriven upwelling appears to enhance onshore larval transport at $\mathrm{LJ}$, because it allows the surface, nearshore expression of the internal bores. In this system local factors that control stratification appear to influence larval settlement.

\section{Acknowledgements}

The US National Science Foundation supported most of this work. The Tinker Foundation provided support for traveling in 1991 and 1992, the Mellon Foundation in 1995. David Field helped in sampling plates and mooring work in 1996. Part of this work was done while M. López spent a sabbatical year at WHOI where the hospitality of Dave Chapman and the Physical Oceanography Department are greatly acknowledged. Partial support for the sabbatical stay came from Fulbright and CONACyT grants. M.L. has also received support from CONACyT grant 
No. G33464-T. Revisions of this manuscript by Andrea Spears, Heidi Fuchs, and two anonymous reviewers are greatly appreciated. The Scripps Institution of Oceanography and the NOAA provided wind and sea level data. This is WHOI contribution number 10,521 .

\section{References}

Bakun, A., Nelson, C.S., 1976. Climatology of upwelling related processes off Baja California. California Cooperative Oceanic Fisheries Investigations Reports 19, 107-127.

Barton, E.D., 1985. Low-frequency variability of currents and temperature on the Pacific continental shelf off northern Baja California, 1978 to 1979. Continental Shelf Research 4, 425-443.

Barton, E.D., Argote, M.L., 1980. Hydrographic variability in an upwelling area off northern Baja California in June, 1976. Journal of Marine Research 38, 631-649.

Bertness, M.D., Gaines, S.D., Stephens, E.G., Yund, P.O., 1992. Components of recruitment in populations of the acorn barnacle Semibalanus balanoides (Linnaeus). Journal of Experimental Marine Biology and Ecology 156, 199-215.

Caffey, H.M., 1985. Spatial and temporal variation in settlement and recruitment on intertidal barnacles. Ecological Monographs 55 (3), 313-332.

Cairns, J.L., 1967. Asymmetry of internal tidal waves in shallow coastal waters. Journal of Geophysical Research 72, 3563-3565.

Cairns, J.L., LaFond, E.E., 1966. Periodic motions of the seasonal thermocline along the Southern California coast. Journal of Geophysical Research 71, 3903-3915.

Chapman, D.C., 1987. Application of wind-forced, long, coastal trapped wave theory along the California continental shelf: measurements and predictions. Journal of Geophysical Research 92, 1798-1816.

Chatfield, C., 1989. The Analysis of Time Series, 4th Edition. Chapman and Hall, New York, 241pp.

Chelton, D.B., 1983. Effects of sampling errors in statistical estimation. Deep-Sea Research 30, 1083-1101.

Connolly, S.R., Roughgarden, J., 1998. A latitudinal gradient in Northeast Pacific intertidal community structure: evidence for an oceanographically based synthesis on marine community theory. American Naturalist 151, 311-326.

Dorman, C.E., Palmer, D.P., 1981. Southern California summer coastal upwelling. In: Richards, F.A. (Ed.), Coastal Upwelling, Vol. 1. American Geophysical Union, Washington DC, pp. $44-56$.

Ebert, T.A., 1983. Recruitment in echinoderms. In: Jangoux, M., Lawrence, J.M. (Eds.), Echinoderm Studies, Vol. 1, Balkema, Rotterdam.

Ebert, T.A., Russell, M.P., 1988. Latitudinal variation in size structure of the west coast purple sea urchin: a correlation with headlands. Limnology and Oceanography 33, 286-294.

Ebert, T.A., Schroeter, S.C., Dixon, J.D., Kalvass, P., 1994. Settlement patterns of red and purple sea urchins (Strongylocentrotus franciscanus and S. Purpuratus) in California, USA. Marine Ecology Progress Series 111, 41-52.

Emery, W.J., Thomson, R.E., 1997. Data Analysis Methods in Physical Oceanography. Pergamon Press, New York, 634pp.

Farrell, T.M., Bracher, D., Roughgarden, J., 1991. Cross-shelf transport causes recruitment to intertidal populations in central California. Limnology and Oceanography 36, 279-288.

Gill, A., 1982. Atmosphere-Ocean Dynamics. Academic Press, San Diego, 662pp.

Godin, G., 1972. The Analysis of Tides. University of Toronto Press, Toronto, 264pp.

Halliwell, G.R., Allen, J.S., 1984. Large-scale sea level response to atmospheric forcing along the west coast of North America, summer 1973. Journal of Physical Oceanography $14,864-886$.

Hatton, H., 1938. Essais de bionomie explicative sur quelques espèces intercotidales d'algues et d'animaux. Annales de L'Institut Océanographique, Monaco 17, 241-348.

Hatton, H., Fischer-Piette, E., 1932. Observations et experiénces sur le peuplement des côtes rocheuses par les Cirripèdes. Bulletin de L'Institut Océanographique, Monaco. (No. 592, Février), 1-15.

Hawkins, S.J., Hartnoll, R.G., 1982. Settlement patterns of Semibalanus balanoides (L.) in the Isle of Man (1977-1981). Journal of Experimental Marine Biology and Ecology 62, 271-283.

Huyer, A.E., Sobey, J.C., Smith, R.L., 1979. The spring transition in currents over the Oregon continental shelf. Journal of Geophysical Research 84, 6995-7011.

Jackson, G.A., 1986. Physical oceanography of the Southern California Bight. In: Eppley, E.R.W. (Ed.), Plankton Dynamics of the Southern California Bight. Springer, Berlin, pp. 13-52.

Lamb, K., 1997. Particle transport by nonbreaking, solitary internal waves. Journal of Geophysical Research 102, $18641-18660$.

Le Fèvre, J., Bourget, E., 1992. Hydrodynamics and behaviour: transport processes in marine invertebrate larvae. Trends in Ecology and Evolution 7, 288-289.

Leichter, J.J., Shellenbarger, G., Genovese, S.J., Wing, S.L., 1998. Breaking internal waves on a Florida coral reef: a plankton pump at work? Marine Ecology Progress Series 166, 83-97.

Lentz, S.J., Winant, C.D., 1986. Subinertial currents on the Southern California shelf. Journal of Physical Oceanography $16,1737-1749$.

Lewis, J.R., 1977. The role of physical and biological factors in the distribution and stability of rocky shore communities. In: Keegan, B.F., Ceidigh, P.O., Boaden, P.J.S. (Eds.), Biology of Benthic Organisms. 11th European Symposium 
of Marine Biology. Galway, October 1976. Pergamon Press, Oxford, pp. 417-423.

List, E.J., Koh, R.C.Y., 1976. Variation in coastal temperatures on the southern and central California coast. Journal of Geophysical Research 81, 1971-1979.

Michener, W.K., Kenny, P.D., 1991. Spatial and temporal patterns of Crassostrea virginica (Gmelin) recruitment: relationship to scale and substratum. Journal of Experimental Marine Biology and Ecology 154, 97-121.

Morris, R.H., Abbott, D.A., Harderlie, E.C., 1980. Intertidal Invertebrates of California. Stanford University Press, Stanford.

Norris, K.S., 1963. The function of temperature in the ecology of the percoid fish Girella nigricans (Ayres). Ecological Monographs 33, 23-62.

Paine, R.T., 1994. Marine Rocky Shores and Community Ecology: an Experimentalist's Perspective. Ecology Institute, Oldendorf, 152pp.

Pineda, J., 1991. Predictable upwelling and the shoreward transport of planktonic larvae by internal tidal bores. Science (Washington D.C.) 253, 548-551.

Pineda, J., 1994a. Internal tidal bores in the nearshore: warmwater fronts, seaward gravity currents and the onshore transport of neustonic larvae. Journal of Marine Research $52,427-458$.

Pineda, J., 1994b. Spatial and temporal patterns in barnacle settlement along a Southern California rocky shore. Marine Ecology Progress Series 107, 125-138.

Pineda, J., 1995. An internal tidal bore regime at nearshore stations along western USA: predictable upwelling within the lunar cycle. Continental Shelf Research 15, 1023-1041.

Pineda, J., 1996. Extreme alongshore variability in barnacle settlement. EOS, Transactions, American Geophysical Union 76, OS94.

Pineda, J., 1999. Circulation and larval distribution in internal tidal bore warm fronts. Limnology and Oceanography 44, $1400-1414$
Pineda, J., Caswell, H., 1997. The dependence of settlement rate on substrate area. Marine Biology (Berlin) 129, 541-548.

Ricketts, E.F., Calvin, J., 1968. Between Pacific Tides, 4th Edition (Revised by J.W. Hedgpeth). Stanford University Press, Stanford, 614pp.

Rosenfeld, L.K., 1990. Baroclinic semidiurnal tidal currents over the continental shelf off northern California. Journal of Geophysical Research 95, 22153-22172.

Roughgarden, J., Gaines, S., Possingham, H., 1988. Recruitment dynamics in complex life cycles. Science (Washington D.C.) $241,1460-1466$.

Shanks, A.L., 1983. Surface slicks associated with tidally forced internal waves may transport pelagic larvae of benthic invertebrates and fishes shoreward. Marine Ecology Progress Series 13, 311-315.

Shanks, A.L., Wright, W.G., 1987. Internal-wave mediated shoreward transport of cyprids, megalopae, and gammarids and correlated longshore differences in the settling rate of intertidal barnacles. Journal of Experimental Marine Biology and Ecology 114, 1-13.

Taylor, P.R., Littler, M.M., 1982. The roles of compensatory mortality, physical disturbance, and substrate retention in the development and organization of a sandinfluenced, rocky-intertidal community. Ecology 63, 135-146.

Winant, C.D., 1974. Internal surges in coastal waters. Journal of Geophysical Research 79, 4523-4526.

Winant, C.D., 1983. Longshore coherence of currents on the Southern California shelf during the summer. Journal of Physical Oceanography 13, 54-64.

Winant, C.D., Bratkovich, A., 1981. Temperature and currents in the Southern California shelf: a description of the variability. Journal of Physical Oceanography 11, 71-86.

Young, C.M., 1990. Larval ecology of marine invertebrates: a sesquicentennial history. Ophelia 32, 1-48. 